\title{
Business strategies in the counterfeit market
}

\author{
Thorsten Staake ${ }^{\mathrm{a}, *}$, Frédéric Thiesse ${ }^{\mathrm{b}}$, Elgar Fleisch ${ }^{\mathrm{a}, \mathrm{c}}$ \\ a Department of Management, Technology and Economics, ETH Zurich, Scheuchzerstrasse 7, 8092 Zurich, Switzerland \\ ${ }^{\mathrm{b}}$ Faculty of Management \& Economics, University of Wuerzburg, Josef-Stangl-Platz 2, 97204 Wuerzburg, Germany

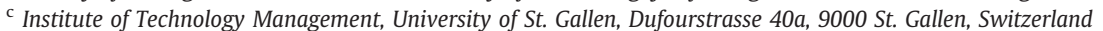

\section{A R T I C L E I N F O}

\section{Article history:}

Received 1 October 2010

Received in revised form 1 February 2011

Accepted 1 March 2011

Available online 11 April 2011

\section{Keywords:}

Counterfeit trade

Strategic groups

Anti-counterfeiting

Brand protection

\begin{abstract}
A B S T R A C T
Counterfeit trade is a multi-billion dollar industry affecting an ever-wider range of goods and markets. Despite the diversity of counterfeit products in terms of complexity, manufacturing techniques, investments in production facilities, potential dangers or value for the users, and degrees of conflict for the counterfeit producers with the local authorities, current academic literature still refers to counterfeit producers as one homogeneous group. Against this background, the present study investigates the existence of strategic groups among counterfeiters based on an empirical examination of counterfeited products using cluster analysis. The results indicate that brand owners are confronted with five different groups of counterfeiters: (1) disaggregators, (2) imitators, (3) fraudsters, (4) desperados, and (5) smugglers. The findings of this study contribute to a more differentiated understanding of each group's learning and growth strategies and help practitioners to better position their companies with respect to the counterfeit market.
\end{abstract}

(c) 2011 Elsevier Inc. All rights reserved.

\section{Introduction}

Product counterfeiting is growing dramatically in terms of volume, sophistication, range of goods, and countries affected (ICC, 2005). The Organization for Economic Co-operation and Development estimates that up to USD 250 billion worth of internationally traded products were counterfeit or pirated in 2007 (OECD, 2009). Product counterfeiting undermines the beneficial effects of intellectual property rights and the concept of branding (Yao, 2005). For individual companies, the presence of a counterfeit market can impact their revenue and goodwill (Nia and Zaichkowsky, 2000; Wilke and Zaichkowsky, 1999) and lead to an increasing risk of liability claims due to substandard imitation products. Nonetheless, the existing body of academic literature only partially reflects the real complexity of the counterfeiting problem. While the demand side of the counterfeit market has received some attention in scholarly journals (e.g., Bloch et al., 1993; Chakraborty et al., 1997; Cordell et al., 1996; Gentry et al., 2001; Grossman and Shapiro, 1988a, 1988b; Wee et al., 1995), very little is known about its supply side (Staake et al., 2009). In particular, hardly any prior research investigates the characteristics and strategies of counterfeit producers.

Against this background, the present study examines the defining characteristics of counterfeit products and strategic groups. The research focuses on actual counterfeit goods - as observed between 2004 and 2007. The use of the term 'counterfeit' follows the definition

\footnotetext{
* Corresponding author.
}

E-mail addresses: tstaake@ethz.ch (T. Staake), frederic.thiesse@uni-wuerzburg.de (F. Thiesse), elgar.fleisch@unisg.ch (E. Fleisch). of counterfeit trademark goods as provided by the Agreement on Trade-Related Aspects of Intellectual Property Rights (TRIPS). According to the TRIPS Agreement, "'counterfeit trademark goods' shall mean any goods, including packaging, bearing without authorization a trademark that is identical to the trademark validly registered in respect of such goods or that cannot be distinguished in its essential aspects from such a trademark, which thereby infringes the rights of the owner of the trademark in question under the law of the country of importation" (WTO, 1994). This definition encompasses breaches of trademark law but excludes piracy, which, by definition, is a violation of copyright and related rights, as well as factory overruns and parallel imports, which are considered a breach of contract rather than a breach of trademark law. The analytical focus is, accordingly, on the production activities of illicit actors.

\section{Theoretical background}

The present study takes a perspective on counterfeiters as members of so-called strategic groups, one of the classical concepts in strategic management research. The term was originally coined by Hunt (1972) in his study of the U.S. home appliance industry to describe the phenomenon of firms within an industry showing similar strategic competencies and competitive capabilities. The notion of strategic groups challenges the view found in the classical industrial organization literature, which posits that firm profitability is a function of industry structure (Mason, 1939; Bain, 1959). In contrast, strategic group theory is based on the observation of large performance variances within a single industry and explains these by the existence of groups of firms clustered around common goals, similar resources, and shared 
assumptions (Porter, 1980; Fiegenbaum et al., 1988). In comparison to the industry at one extreme and the firm at the other, the strategic group poses an intermediate level of analysis, which soon became a widespread taxonomy for strategic management researchers to compare and contrast groups of firms. Several scholarly works were able to demonstrate its validity and usefulness (e.g., Newman, 1973; Porter, 1973; Hambrick, 1983; Fiegenbaum and Thomas, 1990; Parnell and Wright, 1993). Despite some limitations, strategic group analysis today is an established and useful tool in management research.

In contrast, research on the strategies employed by counterfeiters in general is still limited in both focus and scope. Kaikati and LaGarce (1980) were among the first to discuss the general aspects of the counterfeit trade. They differentiate between outright piracy, imitations, and wholesale piracy; briefly sketch generic approaches to prevent counterfeiting; and outline international laws protecting trademarks. As with other early publications (e.g., Hansen, 1978), the authors provide a broad and valuable overview of counterfeit-related issues rather than investigating the problem in greater detail. Higgins and Rubin (1986) provide a deeper analysis by applying the model proposed by Leibenstein (1950) to the consumption of counterfeit Veblenian goods for non-deceptive counterfeit cases or, more specifically, cases where the buyer is aware ex-ante of the illicit nature of the purchased article. Grossman and Shapiro (1988a) also take an analytical perspective on demand-price relationships in markets with both counterfeit and genuine products. In another paper, the authors explain non-deceptive counterfeiting as a disaggregation of product and brand (Grossman and Shapiro, 1988b), an interpretation that proves helpful when discussing the properties of individual groups of counterfeit producers.

In recent years, several studies have contributed to the understanding of consumer behavior in the context of counterfeit purchases (Staake et al., 2009). In contrast, hardly any published work deals with supply-side-related aspects of the counterfeit trade. Harvey and Ronkainen (1998) discuss potential ways in which illicit actors can obtain classified product information. However, their contribution does not seem to reflect the extensive reengineering capabilities of today's counterfeit producers. Olsen and Granzin (1993) investigate the influences of dependence, control, channel conflict, and satisfaction on a dealer's willingness to help a manufacturer combat counterfeiting, thereby allowing for conclusions on the distribution of imitation products.

Green and Smith (2002), seeking to illustrate important characteristics of counterfeit producers, present a highly insightful case study of a major brand owner's success in containing illicit production and distribution of contraband articles in Thailand. Most guidelines that aim to support practitioners in developing and implementing anti-counterfeiting measures are directly derived from observations of established practices but are not supported by empirical findings on the characteristics of the counterfeit market (e.g., Chaudhry et al., 2005; Green and Smith, 2002; Harvey, 1988; Kaikati and LaGarce, 1980; Olsen and Granzin, 1992; Shultz and Saporito, 1996). Consequently, their recommendations do not sufficiently reflect the individual properties and motives of counterfeit producers.

\section{Method}

\subsection{Research design}

The clandestine nature of the counterfeit market and the potential risks for counterfeit producers if their identity is uncovered limit direct access to information from the illicit actors. Though anecdotal evidence and testimony from convicted counterfeiters constitute a potential source for an ex-post validation of selected findings, this information is not suitable as a primary data source. Counterfeiters who are able to hide their operations or are tolerated by local enforcement agencies are likely to be underrepresented within this accessible group, thus introducing an indefinite sampling error. Moreover, the statements from convicted criminals are difficult to verify and are therefore not well suited for a research study.

Instead, this study draws on investigations of counterfeit products in cooperation with industry experts as its primary information source. The underlying assumption is that the characteristics of counterfeit products allow for conclusions concerning the reengineering capabilities of, properties of, and investment in corresponding production facilities, the functional quality of the products, and, consequently, the likely strategic positioning of a counterfeiter's venture. The research method accordingly followed a four-step process. First, scales for the evaluation of counterfeit products were developed in cooperation with two groups of anti-counterfeiting experts. Second, data on counterfeit products were collected from a broad range of affected companies and, in a third step, examined via cluster analysis. Finally, the identified product clusters were enriched with additional data and discussed with industry experts to expand the strategic profiles of associated illicit manufacturers.

\subsection{Evaluation scale development}

In the first phase, two non-overlapping groups A1 and A2, each comprising nine representatives from industry and customs, contributed to the design of the evaluation scales used in the study. The members of these groups were recruited for two previous anticounterfeiting initiatives (the STOP project, funded by the European Commission, and a counterfeit protection benchmarking project led by the authors). This group was complemented with experts where contacts were established at conferences on brand protection. All of the industry experts had three or more years of experience on related issues and represented companies that produce well-known brands that are frequent targets of the counterfeit actors or manufacture high-risk products for which individual cases require extensive investigation. The represented industries include luxury goods, fastmoving consumer goods, consumer electronics, pharmaceuticals, aviation, and automobiles.

Interviews with subgroup A1 consisting of anti-counterfeiting experts provided the information needed to develop constructs that are suitable for describing the substantial characteristics of counterfeit products. The participants were asked to identify the five most important characteristics of counterfeit articles that allow for drawing conclusions on the strategies of counterfeit producers. The choice of variables used to group observations is a crucial step in the application of cluster analysis (Ketchen and Shook, 1996). Because the present study is explorative in nature, with a focus on theory building rather than testing, a cognitive approach was chosen to define the clustering variables. While both inductive and cognitive techniques can generate a rich description of the sample's characteristics (Meyer et al., 1993), the latter technique was preferred because it captures the experiences of industry experts and thereby enhances the confidence that the variables are relevant and meaningful (Ketchen and Shook, 1996; application, e.g., Mascarenhas and Aaker, 1989; Reger and Huff, 1993).

The five properties most often stated by members of group A1 are: (v1) visual quality, (v2) functional quality, (v3) product complexity (i.e., adding a counterfeit label to a complex generic product only leads to a low score), (v4) potential loss or danger for the user, and (v5) degree of conflict with the law in the country of production. Furthermore, the group members suggested a second set of three attributes that require a higher degree of interpretation: (v6) estimated investment in production facilities and organization, (v7) estimated specialization regarding product and brand selection, and (v8) estimated output given the (most likely) applied production technology. The research team, after consultation with the experts, developed the measurement scale for each variable to ensure comparability among different analyses. 
Subgroup A2 of the anti-counterfeiting experts subsequently validated the scales in a discussion round using examples of counterfeit articles. In line with their colleagues from group A1, the experts showed a high level of confidence concerning the applicability and completeness of the aforementioned variables. Table 1 summarizes the suggested scales for each dimension.

\subsection{Data collection}

For the actual data collection phase, 112 companies (later referred to as group B) were contacted and asked whether they could provide access to recently seized counterfeit articles and if possible to discuss the characteristics of these products with anti-counterfeiting or production experts within their companies. The willingness to support the study was high: $25 \%$ of the contacted enterprises provided the required information; $65 \%$ refused to participate, mainly due to concerns over discussing delicate issues with people outside the firm (60\%) or without giving any specific reason (40\%); and 10\% claimed not to have samples of counterfeit articles on hand.

Table 1

Scale of variables.

v1: Visual quality

$1=$ Counterfeit origin obvious for non-expert without closer inspection

$2=$ Counterfeit origin obvious for non-expert only after closer inspection

3 = Counterfeit can be recognized by suspicious consumer only after closer inspection

$4=$ Difficult to distinguish for product expert

$5=$ Difficult to distinguish for counterfeit expert

v2: Functional quality

$1=$ Counterfeit has no functionality/effect

$2=$ Very limited functionality for a short time

3 = Functionality comparable to significantly lower compared to genuine lowcost alternative

$4=$ Functionality comparable to genuine low-cost product

$5=$ Functionality equal to generic product

v3: Product complexity

$1=$ Only label attached

$2=$ T-shirt, belt

$3=$ Quality hand bag

$4=$ Medium to high quality mechanical watch, hand mixer, simple combustion engine

$5=$ TV and more complex products

v4: Potential loss or danger for user

$1=$ No significant financial loss

$2=$ Some financial loss (10 EUR to 100 EUR)

$3=$ Considerable financial loss (over 100 EUR)

$4=$ Threat to health and safety (e.g. allergic reaction, bruises, burns)

$5=$ Potential deadly injuries

v5: Degree of conflict with law

$1=$ Tolerated by authorities in country of production

$2=$ Tolerated with some connections to enforcement agencies

$3=$ Tolerated only with very good connections

$4=$ Risk of considerable punishment

$5=$ Risk of life time imprisonment or death penalty

v6: Investment in production facilities and organization

$1=$ Less than 5000 EUR

$2=5000$ to 50,000 EUR

$3=50,000$ to 500,000 EUR

$4=500,000$ to $5,000,000$ EUR

$5=5,000,000$ EUR or more

v7: Specialization

$1=$ Product and brand can be changed at low cost

$2=$ Product category can be changed at low cost

$3=$ Product category fixed, brand can be changed at low cost

$4=$ Highly cost intense to change product

$5=$ Highly cost intense to change brand or product

v8: Output

$1=$ Less than $0.1 \%$ of licit production

$2=$ Less than $10 \%$ of licit production

$3=$ Less than $33 \%$ of licit production

$4=$ Less than $100 \%$ of licit production

$5=$ Output exceeds licit production capacity
As a result, physical meetings (e.g., at the company site or a practitioner conference) were organized with 32 brand protection and manufacturing experts from 28 companies. The members of group B consisting of anti-counterfeiting experts were executives responsible for the companies' brand protection activities or for production management of the legitimate counterparts of the seized articles. Their employers either appeared in a European Customs statistic on frequently counterfeited brands (TAXUD, 2005) or belonged to industries where counterfeit goods result in a high risk for users or consumers (e.g., pharmaceuticals or aviation components).

The data collection phase spanned a 20 -month period. To ensure a broad sample base, at least ten counterfeit cases from each of the following product categories were chosen for further investigation: (i) foodstuffs and alcoholic and other drinks; (ii) perfumes and cosmetics; (iii) clothing and accessories; (iv) electrical equipment; (v) computer equipment (hardware); (vi) watches and jewelry; (vii) cigarettes; (viii) pharmaceutical products; (ix) mechanical parts; and (x) fast-moving consumer goods. Overall, these ten categories make up over $80 \%$ of all counterfeit cases reported by European customs (EC, 2005). Within the sample, each category includes at least one but generally two of the previously contacted brand owners, each with a market share among the top ten within their market segment.

In total, members of group B evaluated the characteristics of 123 different articles based on the aforementioned scale. All articles fit the stringent definition of counterfeit trade as stated in the TRIPS Agreement. This specification is important because practitioners often implicitly subsume, under the umbrella of counterfeit trade, other illicit activities such as parallel imports and factory overruns that do not involve the characteristic production by non-contractually related actors and thus are of limited relevance to the study. Consequently, digital media such as audio CDs, DVDs, and software, as well as toys and games, were beyond the scope of this analysis, as they pose a breach of copyright and related rights rather than a breach of trademark and design rights.

The respondents set their focus on articles from the most recent three to six counterfeit cases in which their company was involved to prevent a selection bias towards extraordinary or particularly spectacular cases. Samples of all but 34 articles were either physically available or shown on photographs during the interviews to reduce errors resulting from a faulty memory of the respondents and to limit the influence of perceived expectations of the interviewers. Table 2 provides an overview of the examined counterfeit articles and the corresponding product categories.

\subsection{Data analysis}

The chosen methodology for the development of the empirical groupings of the products is cluster analysis. Although cluster analysis is a well-established tool for investigating multidimensional constructs, some researchers have often viewed its application with skepticism

Table 2

Industry categories represented in the samples.

\begin{tabular}{|c|c|c|c|}
\hline $\begin{array}{l}\text { Product } \\
\text { category }\end{array}$ & Category description & \multicolumn{2}{|c|}{$\begin{array}{l}\text { Cases in current } \\
\text { sample }\end{array}$} \\
\hline (i) & Foodstuffs, alcoholic and other drinks & 11 & $9 \%$ \\
\hline (ii) & Perfumes and cosmetics & 13 & $11 \%$ \\
\hline (iii) & Clothing and accessories & 20 & $16 \%$ \\
\hline (vi) & Electrical equipment & 9 & $7 \%$ \\
\hline (v) & Computer equipment (hardware) & 9 & $7 \%$ \\
\hline (vi) & Watches and jewelry & 11 & $9 \%$ \\
\hline (vii) & Cigarettes & 10 & $8 \%$ \\
\hline (viii) & Pharmaceutical products & 11 & $9 \%$ \\
\hline (xi) & Mechanical parts & 16 & $13 \%$ \\
\hline \multirow[t]{2}{*}{$(\mathrm{x})$} & Fast moving consumer goods & 11 & $9 \%$ \\
\hline & Other goods & 2 & $2 \%$ \\
\hline
\end{tabular}


(e.g., Barney and Hoskisson, 1990; Reger and Huff, 1993; Wells, 1975). Critiques include a lack of knowledge among users regarding the algorithms (Punj and Stewart, 1983), a lack of underlying theoretical rationale, and a pronounced reliance on researcher judgment (Ketchen and Shook, 1996). This study addresses potential shortcomings in different ways.

Following Ketchen and Shook (1996), extensive within-method and between-method triangulations serve to substantiate the validity of the findings by applying and comparing the results with those of different clustering algorithms and by seeking critical evaluations and interpretation of the findings by industry experts.

Following Punj and Stewart's (1983) recommendation for a small number of group-defining variables in cluster analysis, the analysis only draws on variables $\mathrm{v} 1$ to $\mathrm{v} 5$, which require less interpretation on behalf of the responding experts compared to v6 to v8. Variables v2 and $\mathrm{v} 4$ show strong correlations (see Table 3 ), and $\mathrm{v} 4$ was therefore excluded from the following analysis. Consequently, the following analysis is based on variables v1, v2, v3, and v5.

Empirical studies indicate that iterative clustering algorithms perform better than hierarchical procedures in cases where a suitable starting point and the number of clusters can be specified in advance (Punj and Stewart, 1983). Since hierarchical procedures need no such prior specifications, the present study makes use of a two-stage analysis methodology: a preliminary identification of clusters using Ward's minimum variance method (Ward, 1963), followed by the non-hierarchical, iterative K-means procedure.

Ward's algorithm seems to offer the best performance compared to other hierarchical methods (Edelbrock and McLaughlin, 1980; Kuiper and Fisher, 1975; Mojena, 1977). The centroid clustering and average linkage clustering algorithms, as well as different distance measures (Euclidian distance and squared Euclidian distance), ensure within-method validity. The visual inspection of the Dendrogram generated with the centroid clustering algorithm allowed for the identification of four outliers, which were removed from the data set. The choice of different clustering procedures and similarity measures appears to be non-critical for the given data set because their alteration only leads to small changes in cluster membership (see Table 4).

The preliminary step helps to determine the number of clusters and generates an initial group description for the K-means procedure. Five clusters are identifiable, based on a visual inspection of the hierarchical solution. This step requires some interpretation on behalf of the researcher and thus introduces a potential way of unintentionally influencing the findings (Aldenderfer and Blashfield, 1984). Therefore, adjacent solutions, or solutions composed of four and six clusters, were also taken into account in subsequent analytical steps to allow for their comparison against each other.

The K-means procedure was applied in the second step given its robustness compared to hierarchical approaches (Punj and Stewart, 1983). The results were checked for face validity with the interviewed brand protection practitioners, who felt that the five-cluster solution provided a particularly meaningful differentiation among the counterfeit actors. Moreover, they regarded the grouping as insightful and

Table 3

Pearson correlations and descriptive statistics of the samples.

\begin{tabular}{lrlllllr}
\hline Variables & Means & $\begin{array}{l}\text { Std. } \\
\text { dev. }\end{array}$ & & 2 & 3 & 4 & \multicolumn{2}{l}{5} \\
\hline 1. Visual quality & 345 & 0.95 & $0.38^{*}$ & $0.30^{*}$ & -0.07 & 0.02 \\
2. Functional quality & 2.55 & 1.13 & & $0.53^{*}$ & $-0.71^{* *}$ & $-0.41^{*}$ \\
3. Product complexity & 1.84 & 0.70 & & & $-0.32^{*}$ & $-0.43^{*}$ \\
4. Potential loss or danger & 2.70 & 1.24 & & & & $0.53^{*}$ \\
5. Conflict with the law & 2.96 & 1.45 & & & & \\
\hline
\end{tabular}

$\mathrm{N}=119$.

* Correlation is significant at the 0.01 level.

** Correlation is significant at the 0.005 level.
Table 4

Invariance to different clustering approaches.

\begin{tabular}{ll}
\hline & $\begin{array}{l}\text { Difference to } \\
\text { reference grouping }\end{array}$ \\
\hline $\begin{array}{c}\text { Centroid clustering, squared Eucledian distance, } \\
\text { no standardization }\end{array}$ & $\mathrm{N}=9(8 \%)$ \\
$\begin{array}{c}\text { Between-groups linkage, squared Eucledian distance, } \\
\text { no standardization }\end{array}$ & $\mathrm{N}=17(14 \%)$ \\
$\begin{array}{l}\text { Ward's method, Eucledian distance, no standardization } \\
\text { Ward's method, squared Eucledian distance, } \\
\text { standardization mean =1 }\end{array}$ & $\mathrm{N}=6(5 \%)$ \\
\hline a Reference: Ward's method, squared Eucledian distance, no standardization.
\end{tabular}

were able to consistently interpret the likely motives of the counterfeit producers.

\section{Findings}

\subsection{Clustering results}

Table 5 outlines the characteristics of the identified groups (a) as well as the characteristics of the non-group-defining variables (b) for each cluster. The results from the F- and Tukey's tests are included, but these should serve only for descriptive purposes because the primary objective in the formation of the groups is to maximize the differences among cases in different clusters. Table 6 shows the distances between cluster centers. The following types of counterfeit products can be distinguished.

Group 1 encompasses counterfeit goods with, at best, average visual quality. The average functional quality is medium, which in most cases allows the owner to use the product but also requires an abdication of durability, stability, performance, or contingency reserves. The typical product complexity is low to medium, and a further analysis shows that many producers within this category target branded articles with high interpersonal values. The expected conflict with law enforcement in the country of production is the lowest among all groups. Consequently, the business model behind this group of products seems to be aimed at offering the benefits associated with a product's brand image without the original products' functional qualities. In other words, illicit manufacturers of this type divide brand and product and sell the brand name alone, usually to customers that are well aware of the counterfeit nature of the products they purchase. We therefore label the counterfeiters disaggregators.

Counterfeit articles from group 2 feature the highest visual and functional quality. Product complexity is highest among all groups, often allowing for actual consumption or usage of the counterfeit articles. The corresponding counterfeit actors within this category seem to face only limited pressure by local enforcement agencies. Because the product-related characteristics within group 2 most closely resemble those of the genuine articles, this type of counterfeiters can be referred to as imitators.

Group 3 is composed of articles with a high visual but low functional quality. Products are typically of medium complexity and are likely to pass as genuine articles if not carefully examined. They may result in a substantial financial loss for the buyer or even endanger the user's health and safety. Consequently, their producers often face considerable punishment if their activities become known. Because the deceptive behavior towards the buyer of the corresponding article constitutes the main characteristic of the producer, this type of counterfeiters can be labeled as fraudsters.

Group 4 contains goods of medium to high visual quality but with the lowest functional quality and product complexity. Products in this category are likely to severely endanger their users or consumers. Consequently, their producers face the most extensive conflict with enforcement agencies. Actors responsible for this group of products 
Table 5

Statistics of group-defining (a) and non group-defining variables (b).

\begin{tabular}{|c|c|c|c|c|c|c|c|c|}
\hline & Variables $^{\mathrm{a}}$ & $\begin{array}{l}\text { Group 1: } \\
\text { Disaggregators }\end{array}$ & $\begin{array}{l}\text { Group 2: } \\
\text { Imitators }\end{array}$ & $\begin{array}{l}\text { Group 3: } \\
\text { Fraudsters }\end{array}$ & $\begin{array}{l}\text { Group 4: } \\
\text { Desperados }\end{array}$ & $\begin{array}{l}\text { Group 5: } \\
\text { Smugglers }\end{array}$ & $F^{\mathrm{b}}$ & Tukey's test ${ }^{\mathrm{c}}$ \\
\hline \multirow[t]{4}{*}{$\begin{array}{l}\text { (a) Group-defining } \\
\text { variables }\end{array}$} & Visual quality & $\begin{array}{l}2.43 \\
(0.79)\end{array}$ & $\begin{array}{l}4.3 \\
(0.60)\end{array}$ & $\begin{array}{l}3.45 \\
(0.74)\end{array}$ & $\begin{array}{l}3.13 \\
(0.76)\end{array}$ & $\begin{array}{l}3.86 \\
(0.66)\end{array}$ & $24.83^{*}$ & $\begin{array}{l}2,3,4,5>1 \\
2>3,4 ; 5>4\end{array}$ \\
\hline & Functional quality & $\begin{array}{l}2.52 \\
(0.51)\end{array}$ & $\begin{array}{l}3.77 \\
(0.43)\end{array}$ & $\begin{array}{l}1.96 \\
(0.63)\end{array}$ & $\begin{array}{l}1.04 \\
(0.21)\end{array}$ & $\begin{array}{l}3.64 \\
(0.50)\end{array}$ & $133.86^{*}$ & $\begin{array}{l}2,5>1 ; 1,3,5>4 \\
2>3,4 ; 5>3\end{array}$ \\
\hline & Product complexity & $\begin{array}{l}1.83 \\
(0.58)\end{array}$ & $\begin{array}{l}2.47 \\
(0.73)\end{array}$ & $\begin{array}{l}1.83 \\
(0.38)\end{array}$ & $\begin{array}{l}1.13 \\
(0.34)\end{array}$ & $\begin{array}{l}1.71 \\
(0.61)\end{array}$ & $19.59^{*}$ & $\begin{array}{l}2>1,3,4,5 \\
1,3>4 ; 4>5\end{array}$ \\
\hline & Conflict with the law & $\begin{array}{l}1.39 \\
(0.50)\end{array}$ & $\begin{array}{l}1.83 \\
(0.48)\end{array}$ & $\begin{array}{l}3.00 \\
(0.53)\end{array}$ & $\begin{array}{l}4.83 \\
(0.39)\end{array}$ & $\begin{array}{l}4.79 \\
(0.43)\end{array}$ & $249.43^{*}$ & $\begin{array}{l}2,3,4,5>1 \\
3,4,5>2 ; 4,5>3\end{array}$ \\
\hline \multirow[t]{5}{*}{$\begin{array}{l}\text { (b) Non-group-defining } \\
\text { variables }\end{array}$} & $\begin{array}{l}\text { Estimated } \\
\text { investment }\end{array}$ & $\begin{array}{l}2.00 \\
(0.67)\end{array}$ & $\begin{array}{l}3.07 \\
(0.69)\end{array}$ & $\begin{array}{l}2.14 \\
(0.64)\end{array}$ & $\begin{array}{l}1.22 \\
(0.42)\end{array}$ & $\begin{array}{l}3.50 \\
(0.76)\end{array}$ & $41.16^{*}$ & $\begin{array}{l}1.3>4 \\
2,5>1,3,4\end{array}$ \\
\hline & $\begin{array}{l}\text { Estimated } \\
\text { specialization }\end{array}$ & $\begin{array}{l}2.61 \\
(0.78)\end{array}$ & $\begin{array}{l}3.47 \\
(0.51)\end{array}$ & $\begin{array}{l}2.76 \\
(0.64)\end{array}$ & $\begin{array}{l}1.78 \\
(0.74)\end{array}$ & $\begin{array}{l}3.56 \\
(0.63)\end{array}$ & $24.45^{*}$ & $\begin{array}{l}1,3>4 \\
2.5>1,3,4\end{array}$ \\
\hline & Estimated output & $\begin{array}{l}2.83 \\
(1.03)\end{array}$ & $\begin{array}{l}3.33 \\
(0.80)\end{array}$ & $\begin{array}{l}2.62 \\
(0.82)\end{array}$ & $\begin{array}{l}2.00 \\
(0.63)\end{array}$ & $\begin{array}{l}3.50 \\
(0.76)\end{array}$ & $11.58^{*}$ & $\begin{array}{l}1>4 \\
2,5>3,4\end{array}$ \\
\hline & $\begin{array}{l}\text { Potential loss or } \\
\text { danger }\end{array}$ & $\begin{array}{l}1.83 \\
(0.83)\end{array}$ & $\begin{array}{l}2.07 \\
(0.87)\end{array}$ & $\begin{array}{l}3.24 \\
(0.58)\end{array}$ & $\begin{array}{l}4.35 \\
(0.78)\end{array}$ & $\begin{array}{l}1.64 \\
(0.63)\end{array}$ & $51.01^{*}$ & $\begin{array}{l}1,3,5>4 \\
2>1,3,4,5\end{array}$ \\
\hline & Number of items & 23 & 30 & 29 & 23 & 14 & & \\
\hline
\end{tabular}

a Means are shown with standard deviations given in parentheses.

b Degrees of freedom for all variables are 4.114 . ${ }^{*} \mathrm{p}<0.001$.

c Groups are significantly different $(\mathrm{p}<0.005)$ for Tukey's test in multiple comparisons of means.

Table 6

Distances between cluster centers.

\begin{tabular}{lllll}
\hline Cluster & Disaggregators & Imitators & Fraudsters & Desperados \\
\hline Imitators & 2.37 & & & \\
Fraudsters & 1.98 & 2.40 & & \\
Desperados & 3.87 & 4.42 & 2.18 & \\
Smugglers & 3.85 & 3.08 & 2.49 & 2.76 \\
\hline
\end{tabular}

are termed desperados in reference to their particularly unscrupulous behaviors.

Group 5 is made up of articles with an average to high visual and functional quality and medium complexity. In this respect, group 5 resembles group 2 . However, the expected conflict with law enforcement agencies is significantly higher because most illicit manufacturers responsible for the products in group 5 target branded products upon which the state imposes high taxes. This type of counterfeiters is referred to as smugglers because they not only significantly profit from brand name-related earnings but also by circumventing taxes (e.g., on tobacco and alcoholic beverages).

Table 7 shows the cross-tabulation of the producers' group memberships and the targeted product categories. The null hypothesis that the counterfeiters' strategy types are randomly distributed across the product categories can be rejected based on the results of Fisher's exact test. In fact, certain strategy types are predestinated for certain counterfeit goods. Smugglers, for example, in addition to gaining brand name-related earnings, rely on realizing profits by evading taxes and therefore are likely to concentrate on bootleg tobacco products and alcoholic beverages. The quality of pharmaceutical products is particularly difficult to assess prior to purchase, making this category attractive for desperados.

However, although the type of producer seems to be dependent on the counterfeit product categories, the former does not pose as a mere surrogate of the latter. Out of the ten product categories, five are manufactured by at least three types of counterfeiters. Perfumes and cosmetics, clothing and accessories, and fast-moving consumer goods are produced by disaggregators, imitators, and fraudsters. Electrical equipment and mechanical parts are produced by disaggregators, imitators, fraudsters, and desperados. The correlation between product category and counterfeiter type therefore does not impose restrictions on the explanatory power of the study.

\subsection{Reliability and validity}

Throughout the study, within-method triangulation serves as an important tool to ensure reliability. The convergence of the results obtained by different clustering algorithms and distance measures indicates a high consistency of the solution, which in turn is a sign of the result's reliability (Hair et al., 2009). Furthermore, a split sample procedure, for which the data set is randomly halved, supports this result. A clustering of the subset also leads to a grouping with five distinct clusters with center means nearly identical to those of the clustering results of the entire data set (see Table 8), which again indicates a high degree of reliability (Hair et al., 2009).

Table 7

Product type vs. group membership.

\begin{tabular}{|c|c|c|c|c|c|}
\hline \multirow[t]{2}{*}{ Product category } & \multirow{2}{*}{$\frac{\text { Group } 1}{\text { Disaggregators }}$} & \multirow{2}{*}{$\frac{\text { Group } 2}{\text { Imitators }}$} & \multirow{2}{*}{$\frac{\text { Group } 3}{\text { Fraudsters }}$} & \multirow{2}{*}{$\frac{\text { Group } 4}{\text { Desperados }}$} & \multirow{2}{*}{$\frac{\text { Group } 5}{\text { Smugglers }}$} \\
\hline & & & & & \\
\hline (i) Foodstuffs, alcoholic and other drinks & 0 & 0 & 5 & 2 & 4 \\
\hline (ii) Perfumes and cosmetics & 2 & 2 & 8 & 0 & 0 \\
\hline (iii) Clothing and accessories & 10 & 8 & 2 & 0 & 0 \\
\hline (vi) Electrical equipment & 1 & 3 & 3 & 2 & 0 \\
\hline (v) Computer equipment (hardware) & 0 & 4 & 4 & 0 & 0 \\
\hline (vi) Watches and jewelry & 6 & 4 & 0 & 0 & 0 \\
\hline (vii) Cigarettes & 0 & 0 & 0 & 0 & 10 \\
\hline (viii) Pharmaceutical products & 0 & 0 & 0 & 10 & 0 \\
\hline (xi) Mechanical parts & 1 & 3 & 3 & 9 & 0 \\
\hline (x) Fast moving consumer goods & 2 & 5 & 4 & 0 & 0 \\
\hline Other goods & 1 & 1 & 0 & 0 & 0 \\
\hline
\end{tabular}


Table 8

Group characteristics of holdout samples.

\begin{tabular}{|c|c|c|c|c|c|c|}
\hline Group-defining variables & Group 1: Disaggregators & Group 2: Imitators & Group 3: Fraudsters & Group 4: Desperados & Group 5: Smugglers & $\mathrm{F}^{\mathrm{a}}$ \\
\hline Visual quality ${ }^{\mathrm{b}}$ & $2.46(0.60)$ & $4.26(0.32)$ & $3.23(0.36)$ & $3.11(0.36)$ & $4.00(0.00)$ & 19. $08^{*}$ \\
\hline Functional quality & $2.54(0.27)$ & $3.68(0.34)$ & $2.31(0.40)$ & $1.01(0.00)$ & $4.00(0.00)$ & $52.72 *$ \\
\hline Product complexity & $1.85(0.14)$ & $2.63(0.58)$ & $1.77(0.19)$ & $1.11(0.11)$ & $1.80(0.70)$ & $11.79^{*}$ \\
\hline Conflict with the law & $1.54(0.27)$ & $1.95(0.16)$ & $3.15(0.14)$ & $4.78(0.19)$ & $4.80(0.20)$ & $120.57^{*}$ \\
\hline Number of items & 13 & 19 & 13 & 9 & 5 & \\
\hline
\end{tabular}

a Degrees of freedom for all variables are 4,54 . ${ }^{*} \mathrm{p}<0.001$.

b Means are shown with standard deviations given in parentheses.

Care in validation is essential to ensure that a meaningful and useful grouping of observations was reached. In this context, reliability as demonstrated above is a necessary but not sufficient condition (Kerlinger and Lee, 1999). To assess the validity of the findings, the insights and experiences of external practitioners can allow for a between-method triangulation, as their perspectives likely differ from the researchers' expectations and judgments (Ketchen and Shook, 1996). Therefore, the group A3 of industry-affiliated brand protection and anti-counterfeiting specialists, and not those from group A1, A2, or B, validated the findings against the background of their external expert knowledge. The respondents, who included four brand protection experts, three production experts, and two marketing managers, found the five-cluster solution to clearly reflect the supply side of the counterfeit market. Again, most of the industry experts were able to provide a consistent analytical interpretation of the results without prior explanation.

\section{Discussion}

The results of the data analysis support the existence of five types of counterfeit producers, each with different production capabilities, different focuses with regard to visual and functional quality (i.e., different emphasis on the consumers' pre-purchase and postpurchase experiences), and different associated risks with respect to prosecution. This positioning, either because of external constraints or as a result of deliberate choice, can be interpreted as distinct strategies of the counterfeit producers. To further understand the profiles of the five identified strategic groups, semi-structured interviews and group discussions with anti-counterfeiting experts from industry and customs officials (i.e., expert groups A1 through A3) were conducted. The group characteristics were discussed against the background of the non-group-defining properties (i.e., variables v5, v6, and v7) as well as internal company information provided by the experts (i.e., internal documentations of counterfeit cases including raids, confiscations of stocks, and seizures of production machinery). The following paragraphs summarize the propositions that were made throughout the talks regarding the existence of strategic groups among the counterfeiters (see Table 9 for an overview) and the starting points for the development of counterstrategies.

The group of disaggregators focuses on products with an average functional quality. Targeted categories are generally clothing, accessories, and consumer goods with high interpersonal values, though their activities are not limited to these products. The business case seems to build upon realizing brand name-related earnings with minimal investment in production facilities. Here trademarks enrich generic goods, and substandard products merely serve as a carrier of a trademark (e.g., one type of handbag that is available with various labels). The low to average complexity of the counterfeit articles supports this conjecture. A low investment in machinery and facilities limits financial losses in the case of raids but also confines production to easy-to-manufacture goods. Very often, these products are of inferior quality and must sell as non-deceptive counterfeits for a fraction of the original product's price. As low sale prices do not justify expensive shipment strategies or direct selling, counterfeiters use large consignments to export their goods and rely on middlemen in destination countries to supply street vendors. This strategy not only reduces the illicit manufacturer's profit margin but also makes the products susceptible to seizures.

As a considerable part of the illicit value chain is in the country of sale, the extent of the corresponding counterfeit articles greatly depends on the efficiency of the enforcement activities in this country. Potentially effective ways to combat disaggregators include public campaigns that improve consumer awareness and decrease the willingness to search and purchase counterfeits as well as the confinement of markets where the counterfeits are offered.

Table 9

Profiles of strategic groups.

\begin{tabular}{|c|c|c|c|c|c|}
\hline & Disaggregators & Imitators & Fraudster & Desperados & Smugglers \\
\hline Capabilities & $\begin{array}{l}\text { - Established production network } \\
\text { or develop own production skill } \\
\text { - Flexibility to follow new trends } \\
\text { quickly }\end{array}$ & $\begin{array}{l}\text { - Solid re-engineering } \\
\text { and engineering skills } \\
\text { - Extended production } \\
\text { capabilities }\end{array}$ & $\begin{array}{l}\text { - Some production } \\
\text { capabilities }\end{array}$ & - Ability to conceal illicit activities & $\begin{array}{l}\text { - Manage network of criminal actors } \\
\text { - Money laundering } \\
\text { - Insulating individual steps within } \\
\text { the value chain from each other }\end{array}$ \\
\hline $\begin{array}{r}\text { Business } \\
\text { model }\end{array}$ & $\begin{array}{l}\text { - Brand imitation as dominant } \\
\text { source of income } \\
\text { - Serve customers' desire to signal } \\
\text { wealth and status }\end{array}$ & $\begin{array}{l}\text { - Brand imitation as } \\
\text { accelerator } \\
\text { - Compatible products } \\
\text { at low price }\end{array}$ & $\begin{array}{l}\text { - Brand imitation as } \\
\text { enabler for goods } \\
\text { - Deceit of customer }\end{array}$ & $\begin{array}{l}\text { - Brand imitation as enabler for } \\
\text { selling dangerous products } \\
\text { - Deceit of customer }\end{array}$ & $\begin{array}{l}\text { - Brand imitation to improve market } \\
\text { access } \\
\text { - Evading taxes } \\
\text { - Low production costs }\end{array}$ \\
\hline $\begin{array}{l}\text { Strategic } \\
\text { focus }\end{array}$ & $\begin{array}{l}\text { - Flexibility } \\
\text { - Focus on goods with high demand } \\
\text { - Reaping short term benefits }\end{array}$ & $\begin{array}{l}\text { - Competitive } \\
\text { advantage } \\
\text { - Entrepreneurship } \\
\text { - Learning and growth }\end{array}$ & $\begin{array}{l}\text { - Profit orientation } \\
\text { - Opportunism }\end{array}$ & $\begin{array}{l}\text { - Maximum profit orientation with } \\
\text { an absence of ethic standards }\end{array}$ & $\begin{array}{l}\text { - Extend power in criminal network } \\
\text { - Established structures, long term } \\
\text { orientation }\end{array}$ \\
\hline $\begin{array}{l}\text { Typical } \\
\text { products }\end{array}$ & $\begin{array}{l}\text { - Clothing and accessories } \\
\text { - Watches and jewelry }\end{array}$ & $\begin{array}{l}\text { - Clothing and } \\
\text { accessories } \\
\text { - Fast moving consumer } \\
\text { goods }\end{array}$ & $\begin{array}{l}\text { - Perfume and } \\
\text { cosmetics }\end{array}$ & - Pharmaceutical products & - Cigarettes \\
\hline
\end{tabular}


In contrast, imitators produce counterfeit articles with a relatively high visual and functional quality. An analysis of the non-groupdefining variables consistently revealed a high average estimated investment, a high degree of specialization, and a relatively high output of the producers. In many cases, the counterfeits fulfill the needs of the user, but the functional quality is clearly below that of the corresponding genuine products. An important finding from the discussions was that imitators often primarily serve their home markets. Especially in young economies with weak enforcement of intellectual property rights, the use of foreign patents and designs can help companies reduce their effort during the development processes and significantly lower the risks of product launches.

Similarly, trademark infringements can foster sales, thus establishing economies of scale and accelerating experience curve effects. Consequently, counterfeiters within this group are most likely to turn into licit competitors once intellectual property rights become more strictly enforced. Imitators are especially vulnerable to seizures of both the products and production equipment because they have the high cost of material and require the highest investments in production equipment. High seizure rates are likely to alter their business model because they have to apportion the high costs of seized products to those that find their way to the customer.

Fraudsters typically produce articles at a high visual but low functional quality and aim to sell these goods as deceptive counterfeits. They often target products for which the buyer is likely unaware of the existence of the faked articles (e.g., food or fastmoving consumer goods), which allows fraudsters to realize sale prices close to those of genuine products and justifies losses due to eventual seizures. These characteristics seem to be reflected in a low estimated investment in production facilities, which can be regarded as an attempt to preserve flexibility and to limit financial losses if equipment is seized. Several anecdotal examples mentioned by the interviewed experts suggest that fraudsters often aim to infiltrate the supply chain of the licit companies. As a consequence, an analysis of the corresponding tactics employed by fraudsters is crucial for strengthening supply-chain resilience. Seizures are expected to show medium effects and should, especially for higher priced goods, also be part of the prevention strategy.

Desperados bear similar characteristics to fraudsters but take a more extreme position with respect to endangering the well-being of the end-users. They mostly target expensive but easily mimicked products whose quality can hardly be evaluated prior to purchase, such as pharmaceuticals or automotive spare parts.

Desperados balance the severity of the expected punishment if they are convicted against the opportunity for considerable profit, even if most of the fakes are confiscated. To reduce their risk, desperados mostly produce on a small scale. Production equipment can easily be replaced if it is found during brand protection activities. Desperados are probably the most difficult opponents to fight because they may stay profitable even if a large share of their goods is seized. Moreover, desperados also choose expensive shipping methods, such as direct mailings in single quantities that are very difficult to confiscate. Protective measures to prevent the consumption or usage of counterfeits include campaigns to inform potential customers to carefully investigate products, avoid non-official distribution channels (i.e., non-certified internet shops and products advertized in spam emails), and contact the manufacturer in case of any doubt. Another way to reduce counterfeit supply may also include deterrence measures such as consequent information on the punishments that desperados can expect.

Smugglers take on a special position, as they primarily realize profits by evading taxes rather than by gaining brand-related earnings. Prominent examples are smugglers that deal with alcohol or tobacco products. High profits from both utilizing brand related free ring effects and evading taxes oppose stringent actions by government agencies. Common characteristics of the members within this group are strong ties to organized crime, high levels of investment in the protection of their operations, and a high degree of vertical integration from production to distribution. Though the direct financial losses due to seizures are unlikely to alter their business model, seizures increase risks for the actors, who in turn necessitate a higher compensation for their work, become more difficult to hire, and take more care to hide their operations, which in turn also increases the search costs for potential customers. Therefore, seizures, combined with the difficulty to market the products in a strictly controlled environment, seem to be the most promising measure to limit illicit supplies from this source.

\section{Implications for theory and practice}

The present study sheds light on the strategies utilized by counterfeit producers using a cluster analysis of a sample of counterfeited products. The results suggest the existence of five different groups among illicit actors. The existence of each group can be explained using strikingly simple but non-trivial analytical considerations. This knowledge is important to an in-depth understanding of the reasons for the emergence of counterfeiters, the underlying rationale for their strategies, and the development of targeted brand protection measures taking advantage of the specific weaknesses of each group.

Although the study relies on a carefully selected data set, it has a number of limitations worth mentioning. The sample consists of only 119 evaluated products, with resulting group sizes of 14 to 30 elements. With the exception of ten counterfeit articles, all of the evaluated products were seized at European borders or within Europe. Missing groups (e.g., from near-perfect imitations) that are rarely confiscated or from imitations that are never imported to Europe might result in additional types of counterfeit producers. Despite the assertions of brand owners that this is unlikely, their possible existence should be taken into account in future studies. Another limitation is that, with 38 respondents serving as key informants for 123 articles, the true unit of analysis is confounded as in all key informant studies. The lack of direct access to counterfeit producers and the need to employ intermediate stakeholders (e.g., industry experts) might be justified by the practical relevance of the problem of counterfeit trade and the lack of better data.

Despite the limitations, the results and conclusions are relevant for management practice and public policy for several reasons. First, knowledge on the specific types of counterfeit producers is a crucial precondition for developing more concise analyses of the phenomenon and for developing targeted and type-specific countermeasures. A differentiated treatment helps to avoid mistakes that result when averages alone are regarded as sufficient explanation of the phenomenon where two or more characteristic properties can exist. Seizures by customs agents, for example, might have a small impact on counterfeit drugs, whereas similar seizures on counterfeit electronic equipment can entirely alter the business model of the involved illicit actors. Targeted countermeasures that address the weakest spots of the illicit actors' underlying business models may prove essential for enhancing strategies to protect intellectual property for customs and marketing managers.

A type-specific evaluation of the effects of anti-counterfeiting measures allows customs, marketing managers, and policy makers to set priorities in their brand and product protection efforts. Because legitimate companies sometimes face illicit markets similar in size to their own and local judicial systems complicit in counterfeiting, while at the same time having budget constraints to finance protective measures, a prioritization can constitute a means to increase the cost effectiveness of the anti-counterfeiting measures. A type-specific analysis also allows for identifying trends concerning the changes in size of each group and thus for making better projections concerning the future development of the phenomenon. Because the pervasiveness of counterfeit producers in many emerging economies with the associated income and learning effects is likely to influence the 
development of these nations, a type-specific assessment can be beneficial to estimate the future growth of these emerging economies.

From a research perspective, the findings might provide a useful foundation that other studies can build upon using a variety of data sources and methodologies (e.g., customs statistics, case studies, and customer surveys). On the one hand, research that aims at confirming and refining the identified group structures and characteristics of each group of the counterfeiters is necessary. Exemplary research issues include the methods employed for infiltrating licit supply chains, the interrelations between counterfeiters and the brand owners' suppliers, and analyses of the long-term effectiveness of specific counterstrategies. On the other hand, there is potential for more theory-driven studies contributing to the stream of research on strategic groups in general. Examples include studies that specifically investigate the time dimension and the impact of group membership on profitability. The evolvement of counterfeiters over time, transitions from one group to another, and in particular the transformational step from counterfeit producer to a licit manufacturer are still areas lacking robust research.

Comparing and contrasting the existing body of knowledge on organizational learning and new venture strategies to the learning and growth strategies among counterfeiters may therefore be of interest to researchers. The linkages between the strategies of licit manufacturers and their illicit counterparts might become another promising research area. To what extent counterfeiters regard only members of their own strategic group as reference points or rather orient themselves on the strategic moves of brand owners remains an unresolved question. Similarly, it is also conceivable that the business strategies of brand owners are in some way influenced by the actions of counterfeiters. Finally, the results of this study may prove helpful to research on the demand side of the counterfeit market. The role of disaggregators, for example, in consumer behavior, brand value, and demand concerning genuine products constitutes another interesting field for future research.

\section{References}

Aldenderfer MS, Blashfield RK. Cluster analysis. Newbury Part, CA: Sage; 1984. Bain JS. Industrial organization. New York: Wiley; 1959.

Barney JB, Hoskisson RE. Strategic groups: untested assertions and research proposals. Managerial Decis Econ 1990;11(3):187-98.

Bloch PH, Bush RF, Campbell L. Consumer "accomplices" in product counterfeiting. J Consum Mark 1993;10(4):27-33.

Chakraborty G, Allred A, Sukhdial AS, Bristol T. Use of negative cues to reduce demand for counterfeit products. Adv Consum Res 1997;24(1):345-9.

Chaudhry P, Cordell V, Zimmerman A. Modelling anti-counterfeiting strategies in response to protecting intellectual property rights in a global environment. Mark Rev 2005;5(1):59-72.

Cordell VV, Kieschnick RL, Wongtada N. Counterfeit purchase intentions: role of lawfulness attitudes and product traits as determinants. J Bus Res 1996:35:41-53.

EC. Communication from the Commission to the Council, the European Parliament and the European Economic and Social Committee. Brussels, Belgium: Commission of the European Communities; 2005.

Edelbrock C, McLaughlin B. Hierarchical cluster analysis using intraclass correlations: a mixture model study. Multivariate Behav Res 1980;15:299-318.

Fiegenbaum A, Thomas H. Strategic groups and performance: the U.S. insurance industry, 1970-84. Strateg Manage J 1990;11(3):197-215.

Fiegenbaum A, McGee J, Thomas H. Exploring the linkage between strategic groups and competitive strategy. Int Stud Manage Organ 1988;18(1):6-25.

Gentry JW, Putrevu P, Shultz C, Commuri S. How now Ralph Lauren? The separation of brand and product in a counterfeit culture. Adv Consum Res 2001;28:258-65.

Green RT, Smith T. Executive insights: countering brand counterfeiters. J Int Mark 2002;10(4):89-106.

Grossman GM, Shapiro C. Counterfeit-product trade. Am Econ Rev 1988a;78(1):59-75.
Grossman GM, Shapiro C. Foreign counterfeiting of status goods. Q J Econ 1988b;103(1):79-100

Hair JF, Black WC, Babin BJ, Anderson RE. Multivariate data analysis. Upper Saddle River, NJ: Prentice Hall; 2009

Hambrick DC. An empirical typology of mature industrial-product environments. Acad Manage J 1983;26(2):213-30.

Hansen J. The capital of counterfeiting. Duns Rev 1978:69 (October).

Harvey M. A new way to combat product counterfeiting. Bus Horiz 1988;31(4):19-28. Harvey MG, Ronkainen IA. International counterfeiters: marketing success without the cost and the risk. Columbia J World Bus 1998;20(3):37-45.

Higgins RS, Rubin PH. Counterfeit goods. J Law Econ 1986;29(2):211-30.

Hunt MS. Competition in the major home appliance industry, 1960-1970. Cambridge, MA: Harvard University Press; 1972.

ICC. Current and emerging intellectual property issues for business - a roadmap for business and policy makers. Document no 450/911 Rev. 6. Paris, France: International Chamber of Commerce; 2005.

Kaikati JG, LaGarce R. Beware of international brand piracy. Harv Bus Rev 1980;58(2): $52-8$.

Kerlinger FN, Lee HB. Foundations of behavioral research. Belmont, CA: Wadsworth Publishing; 1999.

Ketchen DJ, Shook CL. The application of cluster analysis in strategic management research. Strateg Manage J 1996;17(6):441-58.

Kuiper FK, Fisher LA. A Monte Carlo comparison of six clustering procedures. Biometrics 1975;31:777-83.

Leibenstein H. Bandwagon, snob, and Veblen effect in the theory of consumers' demand. QJ Econ 1950;64(2):183-207.

Mascarenhas B, Aaker DA. Strategy over the business cycle. Strateg Manage J 1989;10(3): 199-210.

Mason ES. Price and production policies of large-scale enterprises. Am Econ Rev 1939;29(1):61-74.

Meyer AD, Tsui AS, Hinings CR. Configurational approaches to organizational analysis. Acad Manage J 1993;36(6):1175-95.

Mojena R. Hierarchical grouping methods and stopping rules: an evaluation. Comput J 1977;20(4):359-63.

Newman HH. Strategic groups and the structure-performance relationship: a study with respect to the chemical process industries. PhD thesis, Harvard University, Cambridge, MA, 1973.

Nia A, Zaichkowsky JL. Do counterfeits devalue the ownership of luxury brands? J Prod Brand Manage 2000;9(7):485-97.

OECD. The magnitude of counterfeiting and piracy of tangible products: an update economic impact of counterfeiting and piracy, part IV. Paris, France: Organisation for Economic Co-operation and Development, 19982009.

Olsen JE, Granzin KL. Gaining retailers' assistance in fighting counterfeiting: conceptualization and empirical test of a helping model. J Retailing 1992;68(1): 90-109.

Olsen JE, Granzin KL. Using channels constructs to explain dealers' willingness to help manufactures combat counterfeiting. J Bus Res 1993;27:147-70.

Parnell JA, Wright P. Generic strategy and performance: an empirical test of the Miles and Snow typology. Br J Manage 1993;4(1):29-36.

Porter ME. Consumer behavior, retailer power, and manufacturer strategy in consumer goods industries. PhD thesis, Harvard University, Cambridge, MA, 1973.

Porter ME. Competitive strategy: techniques for analyzing industries and competitors. New York: Free Press; 1980.

Punj G, Stewart DW. Cluster analysis in marketing research: review and suggestions for application. J Mark Res 1983;20:134-48.

Reger RK, Huff AS. Strategic groups: a cognitive perspective. Strateg Manage J 1993;14(2): $103-24$.

Shultz C, Saporito B. Protecting intellectual property: strategies and recommendations to deter counterfeiting and brand piracy in global markets. Columbia J World Bus 1996;31(1):18-28.

Staake T, Thiesse F, Fleisch E. The emergence of counterfeit trade: a literature review. Eur J Mark 2009:43(3/4):320-49.

TAXUD. Counterfeit and piracy: community-wide statistics for 2004. Brussels, Belgium: European Taxation and Customs Union; 2005

Ward JH. Hierarchical grouping to optimize an objective function. J Am Stat Assoc 1963;58(301):236-44

Wee $\mathrm{CH}$, Ta SJ, Cheok KH. Non-price determinants of intention to purchase counterfeit goods - an exploratory study. Int Mark Rev 1995;12(6):19-46.

Wells WD. Psychographics: a critical review. J Mark Res 1975;12(2):196-213.

Wilke R, Zaichkowsky JL. Brand imitation and its effects on innovation, competition, and brand equity. Bus Horiz 1999;42(6):9-18.

WTO. Trade-related aspects of intellectual property rights. Annex 1C of the "Marrakesh Agreement Establishing the World Trade Organization". Marrakesh, Morocco: World Trade Organization; 1994. p. 342. 15 April, Annex 1C, Section 4, Article 51. Yao JT. Counterfeiting and an optimal monitoring policy. Eur J Law Econ 2005;19(1) 95-114. 